\title{
Learning History with Timelines: Use Cases, Requirements and Design
}

\author{
Evgeny Pyshkin \\ Institute of Computing and Control \\ St. Petersburg State \\ Polytechnical University \\ St. Petersburg, Russia, 195251 \\ Email: pyshkin@icc.spbstu.ru
}

\author{
Nikita Bogdanov \\ Institute of Computing and Control \\ St. Petersburg State \\ Polytechnical University \\ St. Petersburg, Russia, 195251 \\ Email: nik.see.7@gmail.com
}

\begin{abstract}
This paper is focused on using computer timeline based interfaces in the domain of history learning. The paper explains what kind of problems do historians and learners face when they deal with chronologically ordered historical information. We review existing approaches and software tools that support timelines. Based on the timeline metaphor ontological model, we examine major features of existing software tools and introduce some novel elements that might be considered as requirements for further implementations.
\end{abstract}

\section{INTRODUCTION}

A WARENESS technology and pervasive nature of current software transform the university curriculum and computer-assisted learning and teaching environments dramatically. Today software has a strong impact both on technology sensitive disciplines and on liberal arts [1]. Specifically, for the domain of computer-assisted language learning (CALL), Beatty mentioned that current CALL is "an amorphous or unstructured discipline, constantly evolving both in terms of pedagogy and technological advances in hardware and software" [2]. Vice versa, the latter observation can be applied not only to language learning but to various areas of technologydriven education as well.

Let's consider history learning. One definition of history is "a chronological record of significant events (as affecting a nation or institution) often including an explanation of their causes" [3]. Hence, above all others, learning history means learning events, their causes and dependencies. Chronology tables, or timeline charts, are used traditionally in numerous history monographs, biography books, science reviews, and so on. As the number of events and contexts increases, one feels hard to manage all the related information. Timelines created by using special software tools don't simply provide a way to record and store event-related information by using computer databases (and this is kind of computer assistance too). Furthermore, they are designed to provide a specific interface to deal with chronology information in a way that is fast impossible or hardly implementable without computers. Existing solutions include such features as timeline zooming, group editing, nesting timelines, attaching multimedia information, managing references to geography maps, association with information about history artifacts, 3-d visualization, to cite a few. This albeit incomplete list illustrates a real technology-driven transformation of the active learning space achieved with help of the computer and software technology of the day.

The focus of this work is to examine problems that historians and history lovers face when they deal with chronologically ordered information. We try to analyze the timeline metaphor from the ontological perspective in order to discover concepts and features which aren't supported by existing timeline visual interfaces and software solutions.

The remaining text of the paper is organized as follows. In section II we analyze the timeline metaphor in the most common sense. Section III lists existing tools using the timeline metaphor to model time related data and processes. We review basic user interface layout types and major stereotypes and features implemented in selected software tools. In section IV we pay special attention to several approaches used as a kind of formal foundation in timeline processing software. In section $\mathrm{V}$ the timeline ontology is introduced with deeper analysis of modeling timeline and event associations. We explain main elements of the map of timeline related concepts and examine requirements for novel features that are missed in the existing applications including event associations, alternate time scaling with respect to different chronology styles, and regional zooming. In section VI we describe user interface elements supporting timeline and event associations and discuss their implementation in the prototype application.

\section{A TIMELINE METAPHOR}

Time is an immanent attribute of information. Whatever we have as a subject context (e.g. history, literature, music, computer programs, linguistics, etc.), events, concepts, documents, art and engineering artifacts appear and develop in time. Even text semantics and word relatedness often change in time. Attention to temporal information attributes and to possible changes of word usage over time can affect the degree of semantic relatedness [4]. Thus, capturing time related information is an important and complex issue in semantic information retrieval.

In many engineering areas (including software design), visualization is one of known ways to decrease system com- 


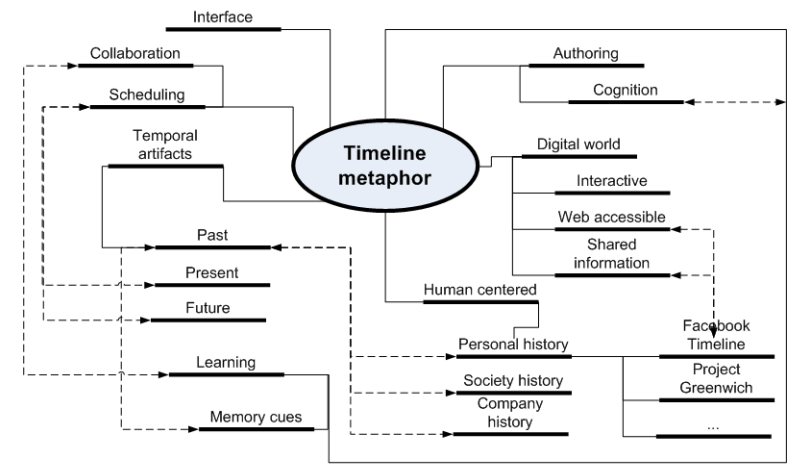

Fig. 1. Timeline metaphor as a map of concepts

plexity and to improve system perception by learners and collaborators. Now let's go back to the history learning issues. Timelines is one of visual ways to organize, manage and display information about events. Wikipedia defines a timeline as " $a$ way of displaying a list of events in chronological order, sometimes described as a project artifact". There might be different kind of events: historical events, cultural events, project milestones or tasks, scheduled appointments, transportation time marks, etymology study points or even research paper publication dates. Thus, on the one hand, timelines are really multidisciplinary visual formalism. On the other hand, it is one of ways to support systematic learning of history related disciplines (like history itself, history of the art, natural science, astronomy, and others).

Despite timelines are usually linked to a graphic design with using bars labelled with dates and associated with event descriptions, Wikipedia timelines (however strange it might be) are presented mostly in textual or table based forms. This makes difficult to zoom events representation to make more emphasis on more important events, to recognize connections between different timelines, to visualize difference of events density in different periods of history, or to highlight different contexts related to the same timeline. Figure 1 shows the sketch of the timeline metaphor in form of a brainstorming map of concepts.

Timelines are more than an attractive and intuitive way to visualize historical information. Project management and collaborative work organization is currently a vast area of using a metaphor of the timeline. It allows combining the broader project view of planned and completed activities with coordinated end user oriented facilities focused upon the specific tasks and events related to the team members [5], [6].

More data people tend to collect, more interests grow in finding out new models to organize information retrieved from the data. Timelines became one of human-computer ubiquitous interfaces used for recording, structuring and browsing personal history [7]. Furthermore, a metaphor of the timeline provides a special searching interface which might be considered as an obvious implementations of the concept of temporally-oriented non-navigational searching: users are open
TABLE I

TIMELINE IMPLEMENTATIONS (PART I)

\begin{tabular}{|l|l|l|}
\hline Name & Main focus & Description \\
\hline SmartDraw $^{a}$ & $\begin{array}{l}\text { Workflow, busi- } \\
\text { ness processes }\end{array}$ & $\begin{array}{l}\text { Commercial business chart soft- } \\
\text { ware supporting flowcharts, deci- } \\
\text { sion trees, cause and effect di- } \\
\text { agrams, timelines, etc. Timelines } \\
\text { are focused on modeling company } \\
\text { workflow, office workers manage- } \\
\text { ment, information flow, reporting } \\
\text { and documentation. }\end{array}$ \\
\hline Asana $^{b}$ & $\begin{array}{l}\text { Team and project } \\
\text { management }\end{array}$ & $\begin{array}{l}\text { Commercial packages for team- } \\
\text { work organization based on task } \\
\text { and responsibility centered model } \\
\text { of the project process flow. }\end{array}$ \\
\hline Timelime $^{c}$ & $\begin{array}{l}\text { Workflow, plan- } \\
\text { ning }\end{array}$ & $\begin{array}{l}\text { Supports creating timelines for } \\
\text { daily activities, team works, calen- } \\
\text { dar related events and task group- } \\
\text { ing. }\end{array}$ \\
\hline $\begin{array}{l}\text { Matchware } \\
\text { Education }^{d}\end{array}$ & $\begin{array}{l}\text { Mind mapping, } \\
\text { project } \\
\text { management }\end{array}$ & $\begin{array}{l}\text { Timeline component is a part of } \\
\text { the MindView application. Sup- } \\
\text { port fixed selection of time periods } \\
\text { scaling (standard, daily, weekly, } \\
\text { historic and geological). Supports } \\
\text { look and fell interface. }\end{array}$ \\
\hline
\end{tabular}

${ }^{a}$ http://www.smartdraw.com/examples/timelines

${ }^{b}$ http://www.asana.com

${ }^{c}$ http://timelimeapp.com

${ }^{d}$ http://www.matchware.com/en/products/mindview/education/timelines.htm

for suggestions since they might have no clear preliminary understanding what document they are trying to locate [8]. What is more, people often prefer browsing over direct search even if the search target is known: "the interface intelligently emphasizes potentially relevant items on a timeline, so that an item can easily be recognized and selected for further inspection" [9].

\section{STATE OF THE ART}

Let us introduce existing tools that use the timeline metaphor for the needs of history learning and explain their focus, current features, and layout models they are based on.

\section{A. Tools}

Table II cites examples of solutions that interest us at most since they can be used as elements of computer-assisted history learning space. Note that a British Library project seems to be a little bit apart of other history chronology based solutions since it represents an approach to expose the $m u$ seum collection artifacts by using the timeline view, without direct relation to the historical event-based context-dependent editable timelines. Table I lists examples of timeline tools used in business oriented applications like project scheduling, staff management, or task planning.

There are three basic types of timeline layouts used by existing implementations:

- Time centered layout uses the event snippets positioned along the timeline bar with detailed descriptions and links to the external resources appeared as popup elements. The Vistorica web site is an example (see Figure 2). In the 
TABLE II

TIMELINE IMPLEMENTATIONS (PARTII)

\begin{tabular}{|c|c|c|}
\hline Name & Main focus & Description \\
\hline $\begin{array}{l}\text { Timeline } \\
\text { Maker }^{e}\end{array}$ & Presentations & $\begin{array}{l}\text { The solution is integrated with } \\
\text { PowerPoint and supports timeline } \\
\text { diagramming for better presenta- } \\
\text { tions. }\end{array}$ \\
\hline TimeGlider $^{f}$ & $\begin{array}{l}\text { History, project } \\
\text { planning }\end{array}$ & $\begin{array}{l}\text { Text based representation with abil- } \\
\text { ities to attach graphics. Support } \\
\text { several configurable event cate- } \\
\text { gories and map tags. }\end{array}$ \\
\hline TimelineJS $^{g}$ & $\begin{array}{l}\text { History, } \\
\text { education, } \\
\text { personal } \\
\text { planning }\end{array}$ & $\begin{array}{l}\text { Web based application for au- } \\
\text { tomatic timeline generation from } \\
\text { Google spreadsheets input data. } \\
\text { Support event layout by using } \\
\text { multi-row timelines. }\end{array}$ \\
\hline TimeToast $^{h}$ & $\begin{array}{l}\text { History, } \\
\text { education, } \\
\text { personal history }\end{array}$ & $\begin{array}{l}\text { Web based application supporting } \\
\text { simple timeline construction able } \\
\text { to be shared share and catego- } \\
\text { rized by using predefined cate- } \\
\text { gories (music, film, science and } \\
\text { technology, business, politics, bi- } \\
\text { ography, art and culture, per- } \\
\text { sonal, history). Popular timelines } \\
\text { are listed on the web site. }\end{array}$ \\
\hline Tiki-toki $^{i}$ & $\begin{array}{l}\text { History, } \\
\text { education, } \\
\text { presentations, } \\
\text { personal history }\end{array}$ & $\begin{array}{l}\text { Web based application for creating } \\
\text { timelines in very visual way (which } \\
\text { include } 3 d \text {-visualization). }\end{array}$ \\
\hline Vistorica $^{j}$ & $\begin{array}{l}\text { History, } \\
\text { education }\end{array}$ & $\begin{array}{l}\text { Historical persons centered appli- } \\
\text { cation. Names and events are man- } \\
\text { aged by using a set of predefined } \\
\text { contexts (events in Europe, science } \\
\text { and technology, European works, } \\
\text { mathematics and engineering, hu- } \\
\text { manities, culture, economy, poli- } \\
\text { tics, military). Integration with ge- } \\
\text { ography information is supported. }\end{array}$ \\
\hline Chronozoom $^{k}$ & $\begin{array}{l}\text { History, } \\
\text { education }\end{array}$ & $\begin{array}{l}\text { Huge open API and history learn- } \\
\text { ing experimental platform for man- } \\
\text { aging user-defined timelines with } \\
\text { rich GUI supporting zooming, cre- } \\
\text { ating nested and shared timelines } \\
\text { linked to a big variety of media } \\
\text { resources. Education perspective is } \\
\text { one of dominating reason. }\end{array}$ \\
\hline $\begin{array}{l}\text { British } \\
\text { Library }\end{array}$ & $\begin{array}{l}\text { Education, } \\
\text { featuring } \\
\text { museum } \\
\text { collections }\end{array}$ & $\begin{array}{l}\text { The application uses timelines to } \\
\text { support exploring the library arti- } \\
\text { fact collection represented collec- } \\
\text { tion items chronologically ranging } \\
\text { from medieval times to the present } \\
\text { day. }\end{array}$ \\
\hline
\end{tabular}

${ }^{e}$ http://www.timelinemaker.com/

$f_{\text {http://timeglider.com }}$

$g_{\text {http://timeline.knightlab.com }}$

${ }^{h}$ http://www.timetoast.com

${ }^{i}$ http://www.tiki=toki.com

$j_{\text {http://vistorica.com }}$

${ }^{k}$ http://www.chronozoom.com

${ }^{l}$ http://www.bl.uk/learning/histcitizen/timeline/acceessvers/index.html

Vistorica there is also a special area to represent event related geographic locations.

- Topic centered layout shifts focus to the event detailed description while timeline bar serves as a navigation interface. The TimelineJS illustrates an idea (see Figure 3).

- Container model shown in Figure 4 is introduced in

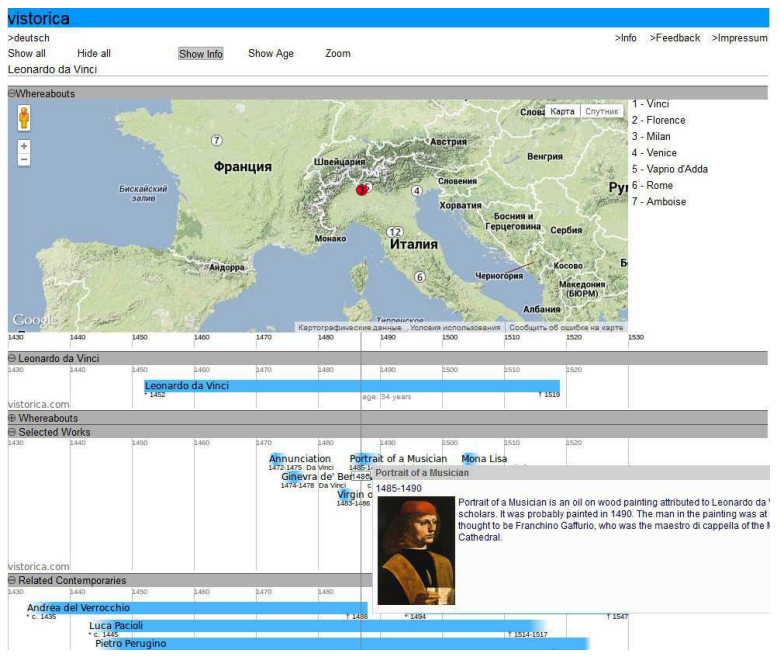

Fig. 2. Time centered layout in Vistorica

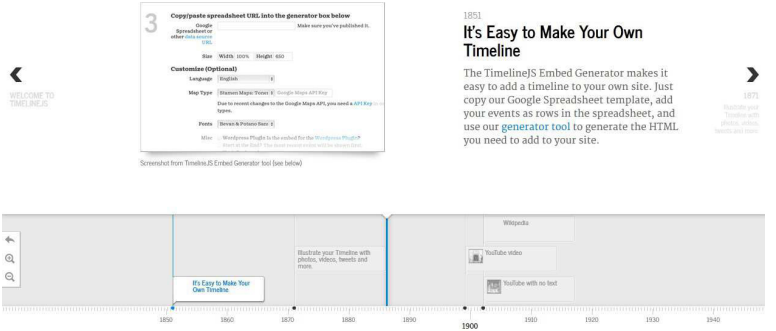

Fig. 3. Topic centered layout in TimelineJS

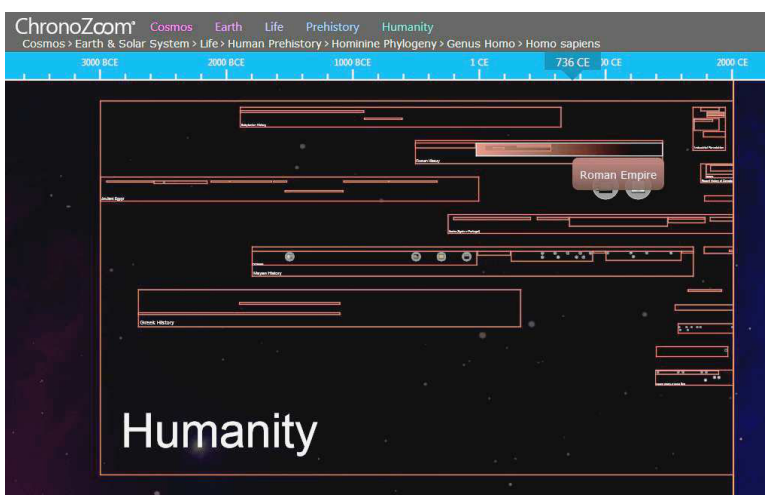

Fig. 4. Chronozoom's container model

the Chronozoom project where a timeline is considered as a container of exhibits with one or more artifacts illustrating the event related topic.

\section{B. Features}

Table III lists major features that general purpose timeline tools support. Through learning and educational perspectives, Chronozoom seems to be potentially the most powerful open-source platform for history visualization [10]. 
Despite many interesting features and layout concepts can be found in existing implementations, there is a space for further improvements with respect to human centered and history learning centered views. In the following sections we propose some feature concepts aimed to improve requirements for further implementations.

\section{RELATED WORK}

There is a variety of research works on generating document summaries to be included into the list of retrieved documents while searching [11], [12]. The main idea is to evaluate the semantic meaning of the document paragraphs and choose the paragraphs with the best meanings for the summary. In the area of timeline visualization, there are aspects of constructing relevant summaries for using them as timeline event headlines. In the work [13] the authors investigate possibilities to construct timeline summaries from collections of news articles available on the web. The main difficulty concerns the problem of choosing the most meaningful news which relate to the event date: the relevant information can be found not only in news appeared exactly on some certain date. They may be published after or before the analyzed date and have references to this date. The complexity of this task grows if we take into account huge amount of news reports received from numerous websites. Users are often interested only to catch the main idea of the news from such a flooding news stream and to discover how do the news appeared on different dates relate to each other. News summarization in the form of timelines may help to reach this goal. Xu et al. introduced a cross-media evolutionary summarization approach which states the formal model that helps deciding whether the news (texts and images) obtained from a certain media or posted by a certain author is the best candidate to be included into the final timeline [14]. They apply an idea of collecting recommendations to the domain of news selection: each candidate news can "recommend" the others and in turn can be "recommended". The candidate's authority increases if $\mathrm{s} / \mathrm{he}$ gets more positive recommendations. Furthermore, recommendations from a more authoritative candidate make other candidates' authority increasing (thus, in a certain sense it is similar to the model used to evaluate research work impact and productivity by using the $\mathrm{H}$-index). This approach can be used as a foundation to automate the process of selecting authoritative and reliable event descriptions to be included into the timeline.

\section{TIMELINE CONCEPT}

As a rule, an event has temporal, spatial and schematic attributes associated with it. That's why investigating relationships, dependencies and correlations between events organized in the chronological order is of much importance [15].

In computer assisted learning systems, the content dependent facilities are necessary in order to express better event semantics and associations. Jouault and Seta cite an example of some military battle description [16]. In addition to timeline positioned events like the battle, the armistice, the treatment

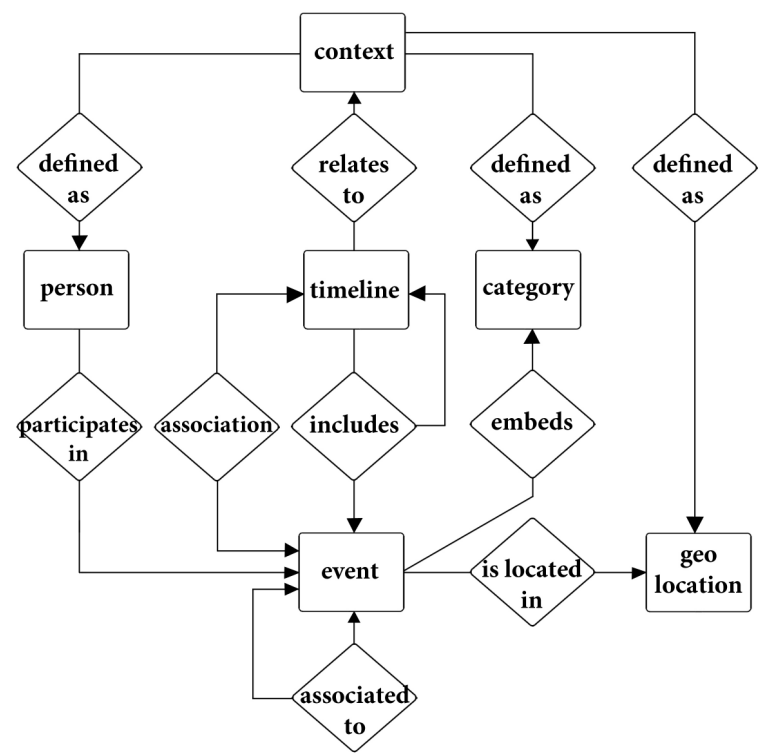

Fig. 5. Core of the timeline ontology

and so on, there are things which are not events but which should be represented in coordination with the timeline (combatant armies, countries that signed a treaty, persons involved to the events, etc.). Every such artifact may have a link to the related timeline. Thus, the associations are as much important as the events.

Here is the list of main timeline ontology entities shown in Figure 5:

- Event (historical event, artifact). Event description is usually represented by the headline summary and associated with date or date range information as well as with links to related resources.

- Category. A category represents the event or timeline specific domain (e.g. history, architecture, countries, music, arts, etc.).

- Timeline context. A context may have similar sense as an event category, but may also relate to geographic locations, persons or other user defines contexts.

- Geographical location. It includes data about geographic coordinates, links to economy, political or cultural contexts bound to geography.

- Person. A person indication may be important due to his or her participation in some event. A person may define a timeline context too.

- Event associations. Associations are ontology elements that are poorly supported in software tools surveyed in Section III, except the implicitly existing temporal associations. However within the framework of history learning and analysis, associations are very important properties.

When teaching history, an instructor might require shifting learner's focus from the timelines or events themselves to the associations, for example: 
TABLE III

SUPPORT FOR MAJOR FEATURES IN EXISTING GENERAL PURPoSe Timeline IMPLEMENTATIONS

\begin{tabular}{|c|c|c|c|c|c|c|c|}
\hline \multirow{2}{*}{ Features } & \multicolumn{7}{|c|}{ Major implementations } \\
\hline & Timeline Maker & TimeGlider & TimelineJS & TimeToast & Tiki-Toki & Vistorica & ChronoZoom \\
\hline Zoom & + & + & + & - & + & + & + \\
\hline Event headlines & + & + & + & + & + & + & + \\
\hline Event details & + & + & + & + & + & + & + \\
\hline Event importance & - & + & - & - & - & - & + \\
\hline Tags & - & + & - & + & + & - & - \\
\hline Images & + & + & + & + & + & + & + \\
\hline Multimedia & - & - & + & + & + & - & + \\
\hline External links & + & + & + & + & + & + & + \\
\hline Mapping to geography & - & - & + & - & - & + & Partially \\
\hline Multiple categories & - & - & - & + & + & + & + \\
\hline User defined categories & via event category & - & + & - & + & - & + \\
\hline Comparing timelines & - & - & - & - & - & + & + \\
\hline Nested timelines & - & - & - & - & - & - & + \\
\hline User defined timelines & + & + & + & + & + & - & + \\
\hline Web access & - & + & + & + & + & + & + \\
\hline Sharing & Partially & + & + & + & + & - & + \\
\hline Group editing & Partially & - & - & - & + & - & + \\
\hline Multiple rows & + & + & + & + & + & + & + \\
\hline Look and feel & + & - & - & - & + & - & + \\
\hline Multiple views & Table & - & + & Table & + & - & - \\
\hline 3D-view & - & - & - & - & + & - & - \\
\hline Search & + & + & - & - & + & - & + \\
\hline Presentation centered & + & - & + & - & + & - & - \\
\hline Information centered & - & + & + & + & + & + & + \\
\hline Integration & PowerPoint & - & - & - & - & - & - \\
\hline Open API & - & - & JSON & - & JSON & - & + \\
\hline Embedding & MS Office & Web & Web & Web & Web & - & - \\
\hline Import Data & + & CSV/JSON & Google spreadsheet & - & Partially from YouTube/RSS & - & Partially \\
\hline Export Data & Text & CSV/JSON & - & - & $\mathrm{CSV} / \mathrm{PDF}$ & - & Partially \\
\hline
\end{tabular}

- How (and why) two (or more) events are related to each other;

- For what reasons an event can be considered as a cause or a consequence of another one;

- How timelines are related, or how events do affect certain timelines;

- What is the similarity between sets of events in different timelines.

Figure 6 introduces possible associations to be considered as a part of the user interface. We borrowed the Chronozoom's concept of a timeline container and added some supplementary constructs to the picture.

The task of comparing industrial revolution periods in Russian and Japanese history serves us as an example. When a teacher (or a learner) considers the industrial transformations in Japan after the long era of Tokugawa family dominance, the events that occurred in Japanese industry, its transportation system, or naval building couldn't be analyzed without paying attention to the Meiji reconstruction period, so these two timelines are deeply related. For the case of Russia we can cite an example of constructivist trends in architecture which are in strong relation with industrialization processes. From the other point of view, the constructivism timeline is affected by the certain event from Kazimir Malevich's biography: Malevich is generally thought as an inventor of the term "constructivism", so there is a dependency between the event and the timeline. Some events may be related despite they are relatively distant: the Russian cruiser "Aurora" was a battleship participated in the Tsushima battle and later won renown with the blank shot that symbolically started the October revolution.

The Figure 6 highlights the issue of implicit conversions that humans often do. An entity considered as an event in one timeline context (e.g. the Tsushima battle within the boundaries of 1904-05 Russo-Japanese war timeline) may be transformed to a timeline if we analyze the battle in details. Unfortunately, there is no direct interface feature that takes this aspect into account.

The next aspect we would like to mention is timeline scales. In all the implementations that we surveyed, the only used time scale refer to traditional (western christian) chronology. However, other traditions to deal with chronology exist and often required to represent timelines in better correspondence to national and cultural contexts and to individual preferences of a historian, to cite a few:

- Russian orthodox church calendar;

- Japanese chronology which refers to their own history pe- 


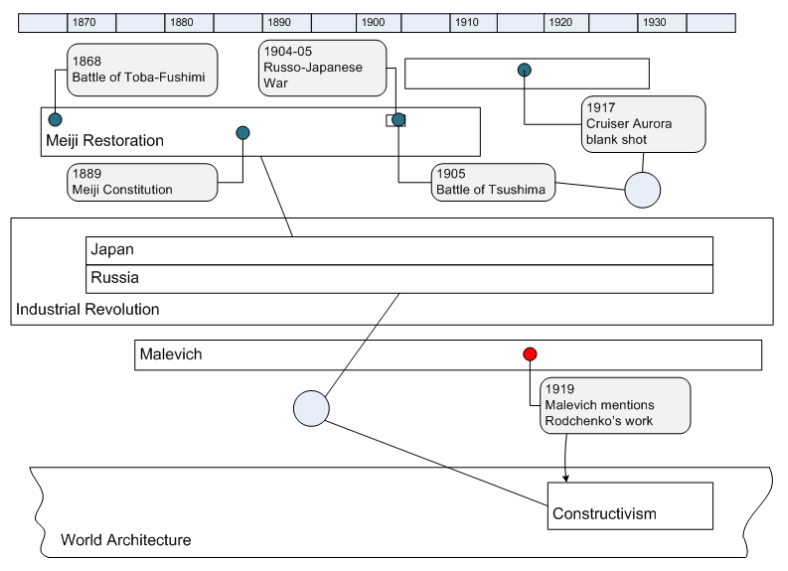

Fig. 6. Artifact associations

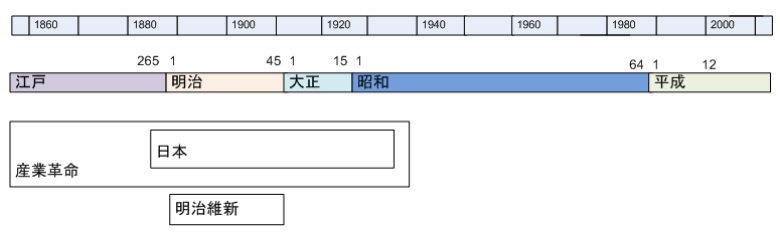

Fig. 7. Example of Japanese chronology timeline bar

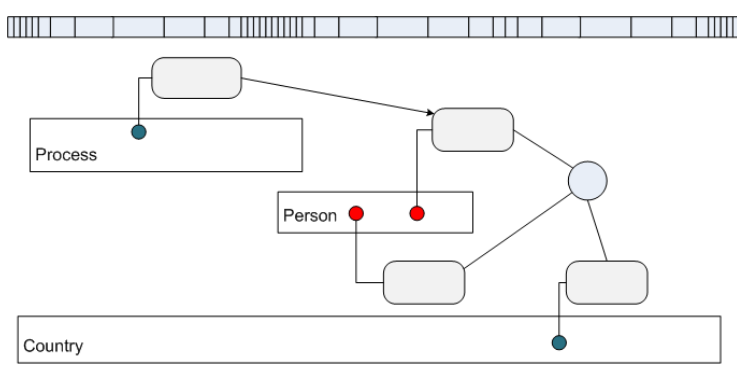

Fig. 8. Flexible time bar and distant associated events

riodization like Jōmon, Yayoi, Kofun and to the Japanese era calendar scheme (nengō) referred to the Imperial practice;

- Chinese Han calendar;

- Non-traditional chronologies.

For certain timelines, historians might require possibility to use parallel subchronologies like for a case of the French Republican Calendar used by the French government for about 12 years from late 1793 to 1805 during the French Revolution. Therefore, an alternate timeline might inherit the core chronology but use parallel time scales as Figure 7 illustrates for the selected events represented earlier in Figure 6.

There are speculative feature concepts that are subjects of further discussions. While learning history people sometimes tend to analyse relationships between very distant events. In this case the possibility can be useful to zoom in or out only some selected time regions allowing focusing on event relationships rather than on the chronology. Figure 8 illustrates this issue.

At last, historians often learn parallels between events in

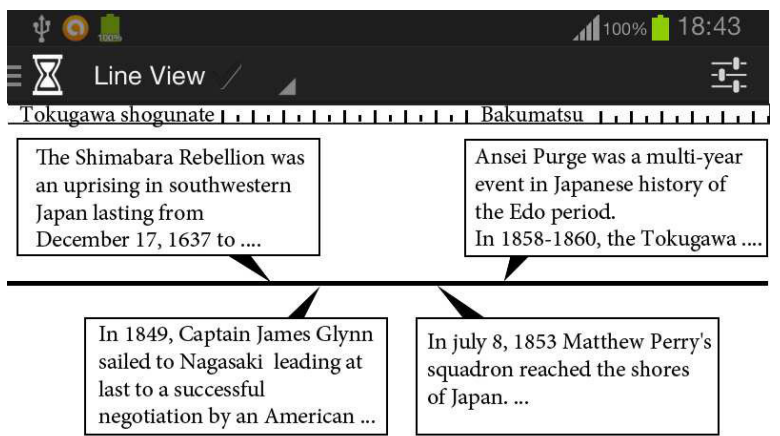

Fig. 9. Headlines and a timeline bar focused view

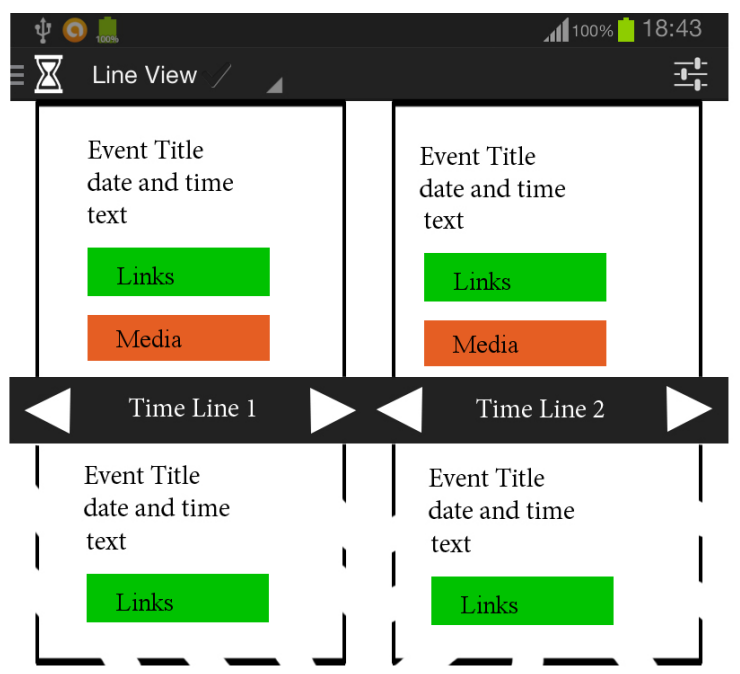

Fig. 10. Descriptions and comparing focused views

quite different time periods (for example, comparing French and Russian Revolutions). In this case a "shift and fix" concept can probably serve the idea: virtually moving one timeline over time with fixing another "in place". It seems that digital timelines can assist such kind of history analysis quite easy and therefore provide a space for a process similar to natural science experiments.

\section{ANDRoid PRototype AppliCATion}

\section{A. Interfaces}

We started implementing timeline views described in the previous section while developing an Android prototype application. There are two traditional views. The view focused on event headlines allows showing events related to one or more categories attached to the time bar. The view focused on event descriptions allows managing detailed event information and comparing detailed descriptions related to the selected timelines as Figure 9 and Figure 10 illustrate.

In addition to traditional views we design the interfaces for map and grid views (shown in Figure 11) which are timeline 


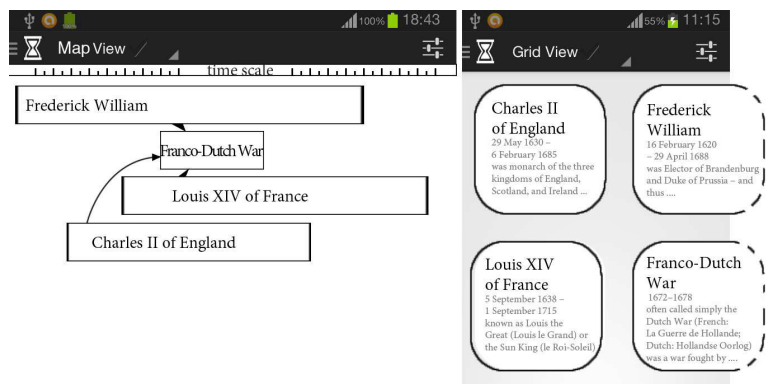

Fig. 11. Map and grid timeline views

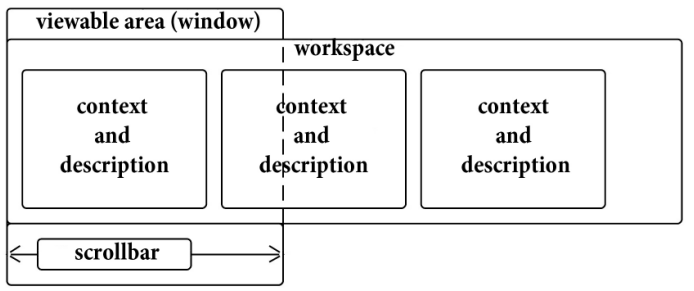

Fig. 12. Sliding window model

association centered. The map view (inspired by a concept of a semantic network) highlights possible relationships between timelines. The map view is aimed to facilitate navigation between related timelines. Evidently, a number of associated timelines can also be considered as a context. The grid view inherits a general concept of a sliding window (see Figure 12) and serves as a kind of an organizational view. It supports timeline arrangements from the user's point of view (similar to application icons) with no direct implications to the timeline relations. For portable devices it is essential to have switching between different views.

\section{B. Database}

Currently the application uses its own database aimed to store two types of events. The first group includes events created manually by the user. The second one corresponds to the events grabbed from the Wikipedia used as a history knowledge source. The database structure shown in Figure 13 is developed according to the timeline ontology model presented earlier.

Below the selected database tables are listed with brief descriptions.

All_Keywords table contains keywords used for searching within the Author, Category, Geo, Person and TimeLine tables.

Synonym table contains keyword synonyms with respect to the context of tables where the data are to be searched. The latter option is necessary since two keywords may be synonyms within the context of one table while keeping independence for another table.

Author_Keyword, Category_Keyword and Person_Keyword are auxiliary tables used for searching.
Author corresponds to the event description origins: who did create the event description and what was the source.

The Timeline, Context, Category, Persons, Event, Association and Geo tables relate to the respective timeline ontological entities. Specifically, the Geo table is connected with other tables (Continent, Country, Nationality, City, etc.) representing different aspects related to the geographical location, political or social associations.

The Person_geo table contains information about geographical locations related to a specific person.

The Event_and_Person table connects events with persons involved.

The Links table contains links to the external resources related to the event.

Despite the database structure may change in the future revisions, it is nevertheless useful to explain better timeline related entities and their associations.

\section{Future work}

Except implementing modules depending on designed interfaces, further steps have to be taken to communicate with external services like Chronozoom by using their open API. The idea is to consider portable application as an interface which would fit better the requirements and stereotypes of a mobile device user. Another challenging problem (which refers strongly to teh domain of semantic information retrieval) is how to extract relevant information about event associations automatically.

\section{CONCLUSION}

Increasing interests to timeline modeling can serve as an example of how new tasks and user interfaces appear as consequence of computing and web technology and applications development. People create timeline based visual interfaces and visual representations of temporal data to improve knowledge acquisition. Information retrieval algorithms and related information processing techniques are not only about accessing some content rapidly and precisely but also about enabling better human or society understanding of explored phenomena, their relations and their mutual dependency with other phenomena and artifacts.

Historians can use timeline based tools while learning, researching or teaching historical periods discoverable with respect to different national and cultural contexts. Indeed, there is a good reason explaining why do many books on history contain chronology tables. Similar to natural sciences where setting up an experiment is a usual way of study, timelines created with computer tools make arranging learning experiments for history education easier. We may collate similar periods in different cultures, or, conversely, analyze comparable events that took place in different epochs and in different places. We are able even to model prefigured events and historical hypotheses.

In so doing, developers are able create a better framework implementing a concept of active learning in tight cooperation with recent achievements of information retrieval methods and software technology. 


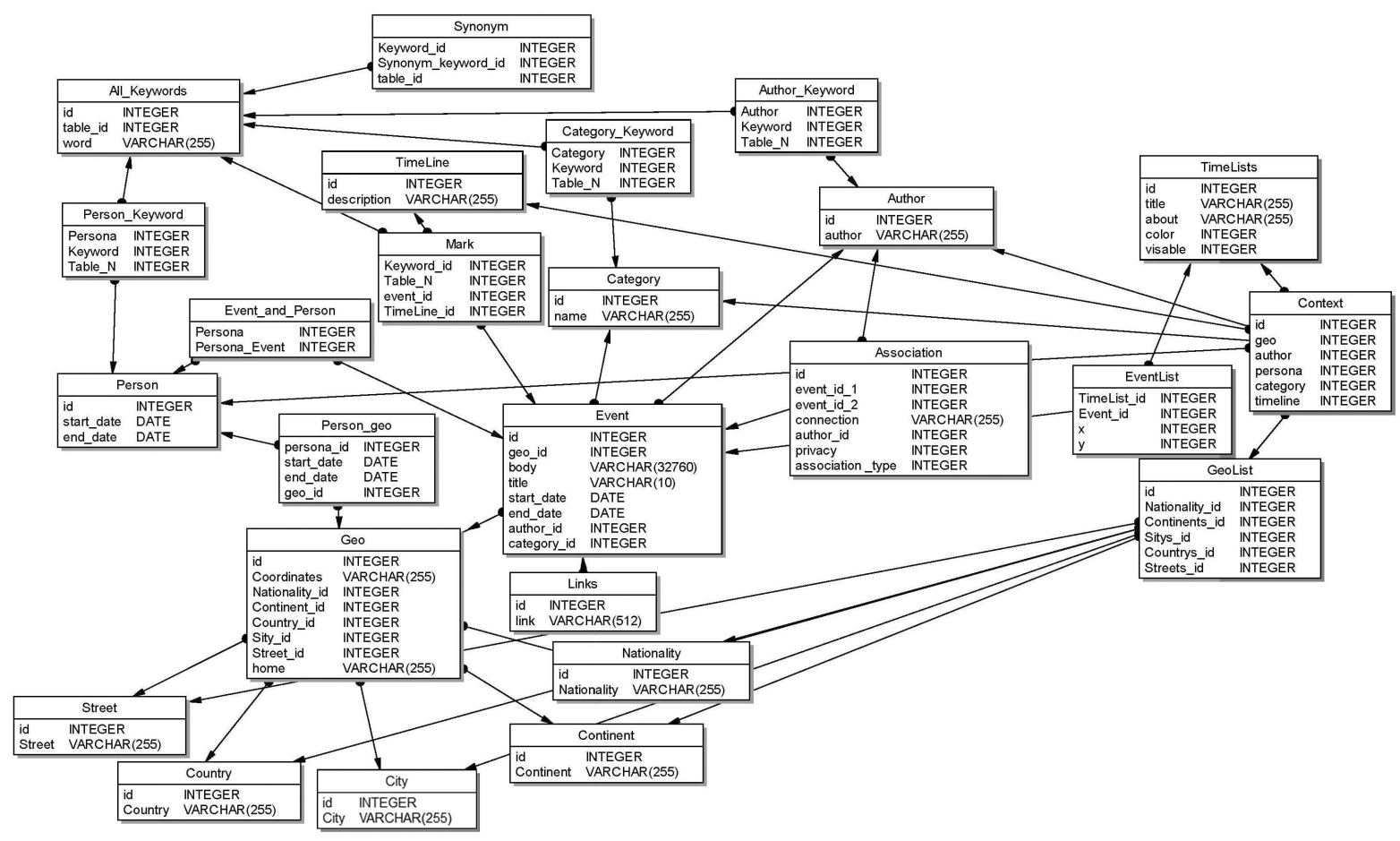

Fig. 13. Database structure

\section{REFERENCES}

[1] E. Pyshkin, "In the right order of brush strokes: a sketch of a software philosophy retrospective," SpringerPlus, no. 186, p. 3:186, 2014.

[2] K. Beatty, Teaching and Researching Computer-assisted Language Learning. 2nd edition. Pearson Education, 2010.

[3] "Merriam-webster dictionary: History." [Online]. Available: http: //www.merriam-webster.com/dictionary/history

[4] K. Radinsky, E. Agichtein, E. Gabrilovich, and S. Markovitch, "A word at a time: Computing word relatedness using temporal semantic analysis," in Proceedings of the 20th International Conference on World Wide Web, ser. WWW '11. New York, NY, USA: ACM, 2011, pp. 337346. [Online]. Available: http://doi.acm.org/10.1145/1963405.1963455

[5] M. Bohøj, N. G. Borchorst, N. O. Bouvin, S. Bødker, and P.-O. Zander, "Timeline collaboration," in Proceedings of the SIGCHI Conference on Human Factors in Computing Systems, ser. CHI '10. New York, NY, USA: ACM, 2010, pp. 523-532. [Online]. Available: http://doi.acm.org/10.1145/1753326.1753404

[6] L. Batrinca, M. T. Khan, D. Billman, B. Aydemir, and G. Convertino, "A timeline visualization for multi-team collaborative planning," in CHI'13 Extended Abstracts on Human Factors in Computing Systems, ser. CHI EA '13. New York, NY, USA: ACM, 2013, pp. 157-162. [Online]. Available: http://doi.acm.org/10.1145/2468356.2468385

[7] E. Thiry, S. Lindley, R. Banks, and T. Regan, "Authoring personal histories: Exploring the timeline as a framework for meaning making," in Proceedings of the SIGCHI Conference on Human Factors in Computing Systems, ser. CHI '13. New York, NY, USA: ACM, 2013, pp. 16191628. [Online]. Available: http://doi.acm.org/10.1145/2470654.2466215

[8] K. Church, "How many multiword expressions do people know?" in Proceedings of the Workshop on Multiword Expressions: From Parsing and Generation to the Real World, ser. MWE '11. Stroudsburg, PA, USA: Association for Computational Linguistics, 2011, pp. 137-144. [Online]. Available: http://dl.acm.org/citation.cfm?id=2021121.2021152

[9] A. Ajanki, M. Koskela, J. Laaksonen, and S. Kaski, "Adaptive timeline interface to personal history data," in Proceedings of the 15th ACM on International Conference on Multimodal Interaction, ser. ICMI '13. New York, NY, USA: ACM, 2013, pp. 229-236. [Online]. Available: http://doi.acm.org/10.1145/2522848.2522870
[10] R. L. Walter, S. Berezin, and A. Teredesai, "Chronozoom: Travel through time for education, exploration, and information technology research," in Proceedings of the 2Nd Annual Conference on Research in Information Technology, ser. RIIT '13. New York, NY, USA: ACM, 2013, pp. 3136. [Online]. Available: http://doi.acm.org/10.1145/2512209.2512217

[11] V. Oleshchuk and V. Klyuev, "Context-aware summary generation for web pages," in Intelligent Data Acquisition and Advanced Computing Systems: Technology and Applications, 2009. IDAACS 2009. IEEE International Workshop on, Sept 2009, pp. 561-564.

[12] S. Satake, S. Ishikawa, D. Vazhenin, and V. Klyuev, "A semantic-based summarizing tool for improving the usability of general purpose search engines," in Pervasive Computing (JCPC), 2009 Joint Conferences on, Dec 2009, pp. 235-238.

[13] G. Binh Tran, M. Alrifai, and D. Quoc Nguyen, "Predicting relevant news events for timeline summaries," in Proceedings of the $22 \mathrm{Nd}$ International Conference on World Wide Web Companion, ser. WWW '13 Companion. Republic and Canton of Geneva, Switzerland: International World Wide Web Conferences Steering Committee, 2013, pp. 91-92. [Online]. Available: http://dl.acm.org/citation.cfm?id= 2487788.2487829

[14] S. Xu, L. Kong, and Y. Zhang, "A cross-media evolutionary timeline generation framework based on iterative recommendation," in Proceedings of the 3rd ACM Conference on International Conference on Multimedia Retrieval, ser. ICMR '13. New York, NY, USA: ACM, 2013, pp. 73-80. [Online]. Available: http: //doi.acm.org/10.1145/2461466.2461480

[15] A. Biswas, B. V. Sagar, and J. Srinivasan, "Managing and correlating historical events using an event timeline datatype," in Proceedings of the 13th International Conference on Database Systems for Advanced Applications, ser. DASFAA'08. Berlin, Heidelberg: Springer-Verlag, 2008, pp. 604-612. [Online]. Available: http://dl.acm.org/citation.cfm?id=1802514.1802580

[16] C. Jouault and K. Seta, "Building a semantic open learning space with adaptive question generation support," in Proceedings of the 21st International Conference on Computers in Education, ser. ICCE'13. Asia-Pacific Society for Computers in Education, 2011, pp. 41-50. [Online]. Available: http://icce2013bali.org/datacenter/ mainconferenceproceedingsforindividualdownload/c1/C1-f-206.pdf 